she was admitted to the dispensary complaining of sorethroat, \&c. She is a stout woman, with a full, red face, and dark hair.

The patient was treated for ordinary sore-throat, and in three days returned complaining of having spots on her legs. At this time she had one spot, red, prominent, and very painful when touched, situated over the right tibia; and one over the left tibia. similar in character, but smaller in size. On Sept. 2nd she complained of much pain from these spots, and, being unable to walk, took to her bed. On the right leg was a swelling about the size of a hen's egg over the anterior border of the tibia, elevated, red in the centre, resembling a bruise at the circumference, ind very painful to the touch. On the left leg was a similar but smaller swelling over the tibia and near the ankle. Smaller spots, but of like character, existed over the styloid processes of the right and left ulnar. There was no marked heat or increase of temperature.

Sept. 8th.-Left arm: One spot between the second and third phalanges of the left hand; a few spots on the outside of the arm near the insertion of the deltoid. Right arm: Wrist swollen, and very painful ; elbow also swollen; some spots on the arm. Left leg: Bruise-like appearance of spot, as before mentioned; fresh spots on inside of leg and behind the knee. Right leg: Same spot present, and still looking like a bruise.

12th.-Fourteen spots on left arm, mostly on the extensor surface. Spots on leg still present. Right arm: Twenty spots, varying in size from that of a pea to that of a sparrow's egg. Wrist and elbow-joints still somewhat swollen, but less painful.

18th.-The spots all present, presenting a bruise-like appearance.

22nd.--Spots very faint. Patient got up on the 21st. On each occasion of a note being made the temperature was taken, but on no occasion had it risen. Circulatory system : No cardiac murmur perceptible. Urinary system: Examined on first occasion only; urine then clear; no albumen.

Remarks by Dr. HawnINs. - While there is no history of rheumatism or rheumatic tendency in the family antecedents, we have a marked neurotic history, the mother having died in an asylum, and a sister having epilepsy frequently for four years, and then having to be placed in an asylum; then we have erythema nodosum in another sister; and we have recurrence of the disease in the case under review-the first time when twenty-four years old, the second when thirty-one years old, and the third when thirty-five years old. The former attacks were, I think, beyond doubt erythema nodosum; the patient herself recognised the resemblance between this attack and her former ones, and the resemblance of her disease to that from which her sister suffered four years ago. This case may be said to resemble rheumatic fever in the following points: Thirst, anorexia, constipation, and sleeplessness; the appearance of the spots and swelling of the joints being preceded on two occasions by sore-throat, then pain and swelling of the joints. It differs, however, from rheumatic fever in there being no rise of temperature and no sweating; and there was no cardiac affection left.

\section{MOUNT GAMBIER HOSPITAL, S.A.}

ABSCESS OF BRAIN; CYST CONTAINING NECROSED BONE; DEATH; NECROPSY; REMARKS.

(Under the care of Mr. A. Worslex Powell, Assistant Colonial Surgeon and Medical Officer.)

H. V-_-, a German, aged twenty-six, three years resident in the colonies, was brought to this hospital by the police on the evening of Feb. 18th. Before the police found him it appears he had been lying in a tent for three days unattended and in a semi-comatose state. When reportcd Dr. Ockley of Penola was sent for and ordered the man to be removed to this institution. Dr. Ockley's notes are as follows:- "H. V_ semi-comatose, with loss of speech. Pupils contracted, with only semi-sensibility. Evidently oppression on brain, probably embolism from some injury or obscure obstruction of the circulation. No opportunity for treatment. Forwarded to Mount Gambier Hospital."

On admission the deceased, aided by a porter, walked to his bed, but he could neither speak nor hear. He seemed in a state of great stupor. Temperature $104 \cdot 6^{\circ}$. Pupils contracted and insensible. He passed a very restless night, tossing about and moaning continually. There was no paralysis.
Feb. 19th.-At 6 A.M. by signs he asked for his trousers, seemed much better, and drank some milk, the temperature being $104 \cdot 8^{\circ}$. He sat upright in bed for nearly half an hour but still could neither speak nor hear. Questions were written, but he did not seem to understand them, making no signs in reply. When asking for his trousers he pointed to his legs and then to some trousers belonging to a patient in the next bed. When his trousers were brought he put them on and seemed satisfied. At 7 A.M. he had a slight epileptiform seizure and relapsed into a semi-comatose state. At 4 P.M. he had strong convulsions, vomited a large quantity of watery fluid, and died shortly after midnight.

Necropsy. - Body well nourished. No external marks of injury either on head or trunk. No traces of syphilis. When removing the skull-cap the saw ran through the left parietal bone immediately above the ear, and a large quantity of pus (greenish in colour and of offensive odour) rushed out. The bone here was but a mere shell, and for a space of ubout one inch in circumference could easily be broken with the finger-nail. The dura mater was very firmly adherent to the bone and could not be separated over a space of about two inches square. The tinger, when introduced into the opening whence the pus was coming, passed immediately into a large cavity, the size of a small orange, the cavity leading into the lateral ventricle. About midway, lying loosely in this cavity, a cyst was found. It was hard, black, and resembled in size and shape a small Barcelona nut. It measured an inch and a quarter in diameter. On opening the cyst, the membrane of which was very tough, there were found three small pieces of necrosed bone. The pus and bone were, of course, verified under the microscope. The heart and lungs were quite healthy; the liver was very much congested, and weighed $5 \frac{1}{4} \mathrm{lb}$.

No history concerning the deceased could be gathered by the police, but on the day following his death a friend who had emigrated with him, and had been his constant companion for some years, was seen by Mr. Powell, who obtained from him the following history: When deceased was fourteen years old he fell from a ladder on to the iron wheel of a barrow, striking his head. He was unconscious for some days, and very ill for over two months. Since then he had had frequent "fits," which left him weak for two or three days. He had had none of these "fits" after coming to the colony until about fourteen months since, so that there was an interval of nearly two years. He suffered greatly from his head, complaining of constant and violent headache. He had frequently taken medical advice for this, but always without relief. He also complained of being severely troubled by cramp. He was a temperate, hard-working man; could do a hard day's work with any man, except for a few days after the "fits." He had been working up till February 13th. He never had any symptoms of paralysis.

Remarks by Mr. PowkLL. - I am not aware whether any similar case is recorded. In vol. i. of "Holmes's System of Surgery," third edition, a case is mentioned of a cyst containing pus following diseased temporal bone. In this case there was no disease of the ear, there had never been any discharge from it, and the temporal bone was quite healthy. There was no sign of any scar on the scalp over the injured bone. It seems marvellous that in such a case the man should be able to work and go about with all his faculties unimpaired until a few days before his death.

\section{等ledical Socteties.}

\section{MEDICAL SOCIETY OF LONDON.}

\section{Littre's Hernia.-Simple Meningitis.}

THe last ordinary meeting of this Society was held on Monday last, Mr. R. Brudenell Carter, F.R.C.S., President in the chair.

Mr. J. H. Morgan read a paper on a case of Littre's Hernia. Having described Littre's original cases, he proceeded to relate his case, which was interesting, in addition to its rarity, from the circumstance that no gangrene of the herniated portion of the intestine occurred. The patient was an elderly Foman aged sixty-four, who had suffered from constipation for from two to three years, and had also wasted considerably. Some blood was passed per rectum from time to time. Purgatives and enemata were ordered 